\title{
Case report. Beklemde herniatie van dunne darm bij chronische suprapubische katheter
}

\author{
Robin Hoendervangers ${ }^{1}$ - Eric H. G. M. Oomens ${ }^{1}$. Joost A. P. Leijte ${ }^{1}$. Deric K. E. van der Schoot ${ }^{1}$
}

Published online: 19 March 2018

(c) The Author(s) 2018.

\section{Samenvatting}

Wij presenteren een casus van een beklemde herniatie met dunne darm bij een patient die chronische een suprapubische katheter in situ had. De casus betreft een 87-jarige man, die zich presenteert met een forse hernia, ter plekke van het litteken van zijn voormalige suprapubische katheter (SPC), die tien jaar daarvoor geplaatst was vanwege een atone blaas. Aanvankelijk werd de hernia conservatief behandeld. Na enkele maanden werd echter een beklemde breuk geconstateerd, waarna $15 \mathrm{~cm}$ necrotische dunne darm werd verwijderd. Uit de literatuur is een enkel geval van herniatie na SPC bekend, maar niet eerder werd een beklemde dunne darm beschreven. Herniatie is een zeldzame, maar potentieel ernstige complicatie van SPC-plaatsing. Herkenning van een breuk, en zo nodig preventieve correctie, kan een ernstige complicaties, zoals in deze casus beklemming van breukinhoud, voorkomen.

Trefwoorden parastomale hernia $\cdot$ littekenbreuk $\cdot$ suprapubische katheter

\section{Case report. Herniation of incarcerated small bowel after chronic suprapubic cystostomy}

\begin{abstract}
We present a case of incarceration of small bowel following suprapubic cystostomy. Case: An 87-year old male presented with an incisional hernia ten years after suprapubic catheter placement. Eventually treated conservatively, in a later stadium $15 \mathrm{~cm}$ of incarcerated necrotic small intestine was resected. There are few cases of incisional hernia following suprapubic cystostomy. This is the first case to report on incarcerated small intestine at the site of the SPC. Conclusion: Early detection of a herniation along the (former) SPC-tract is important. Early repair could prevent further complications such as incarceration of intestine.
\end{abstract}

Keywords herniated small intestine $\cdot$ incisional hernia $\cdot$ suprapubic cystostomy

\section{Introductie}

Suprapubische katheterisatie (SPC) wordt vaak ingezet in de urologische praktijk en is een veelgebruikte manier van urineafleiding. Meerdere complicaties van SPC zijn beschreven. De meeste complicaties doen zich op de lange termijn voor. Wij presenteren een casus van een beklemde dunne darm bij een littekenbreuk bij een bestaande SPC.

Robin Hoendervangers

rhoendervangers@amphia.nl

1 afdeling Urologie, Amphia ziekenhuis, Breda, Nederland

\section{Casus}

Een 87-jarige patiënt presenteerde zich op de Spoedeisende Hulp (SEH) met een pijnlijke zwelling op de plaats van de SPC. De SPC was tien jaar daarvoor geplaatst na een acute urineretentie en een persisterende atone blaas. Aanvankelijk werd een Ch12-katheter geplaatst. Deze werd stapsgewijs gedilateerd naar een Ch18-katheter. Na acht jaar ontstonden blaaskrampen en trad urinelekkage op langs de SPC. Bij cystoscopie werden drie blaasstenen gezien. Deze stenen werden operatief via de SPC-fistel verwijderd. Postoperatief bleven klachten van lekkage langs de suprapubische katheter bestaan. Ook met een Ch20-katheter persisteerde de urinelekkage. Vanwege verzorgingsproblemen werd besloten de suprapubische katheter permanent te vervangen 


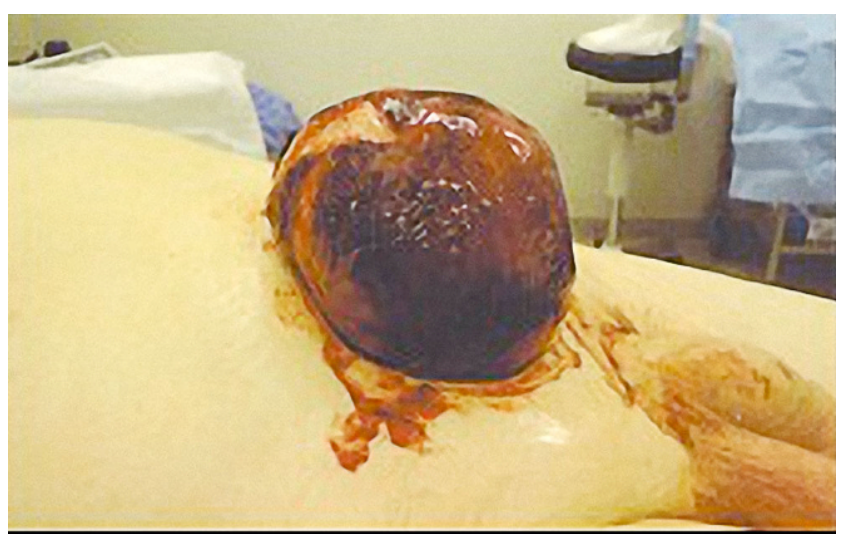

Figuur 1 De herniatie via de SP-opening op de SEH

voor een transurethrale katheter. Het fistel werd verzorgd met een stomazakje. Kort na het verwijderen van de SPC ontwikkelde zich een prolaps ter plaatse van de fistelopening, die aanvankelijk werd geduid als protrusie van de blaaswand. De prolaps werd manueel opgeheven op de polikliniek, en er werden instructies gegeven aan de thuiszorg om de herniatie regelmatig te reponeren. Na vijf maanden meldde patiënt zich op de SEH met een grote pijnlijke zwelling ter plaatse van de voormalige SPC-insteek. Lichamelijk onderzoek toonde een pijnlijke zwelling van $12 \mathrm{~cm}$ (fig. 1). Een direct uitgevoerde CT-scan toonde herniatie van dunne darm (fig. 2).

De patiënt werd acuut geopereerd, waarbij in de breukzak $15 \mathrm{~cm}$ necrotische dunne darm werd gevonden (fig. 3). Er werd 20 centimeter dunne darm gereseceerd, waarna een side-to-sideanastomose werd verricht. Vervolgens werd de blaas losgeprepareerd tot aan het fistel, waarna die werd gesloten. De patiënt herstelde volledig postoperatief. Hij bleef afhankelijk van een transurethrale katheter.

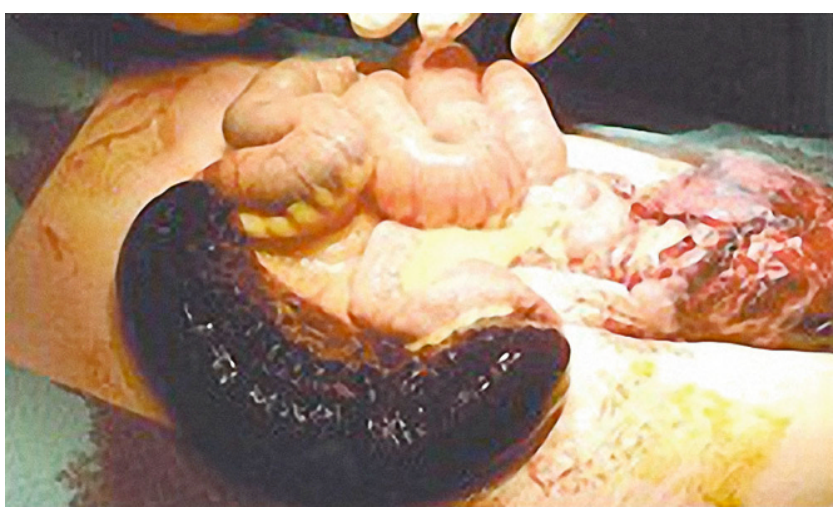

Figuur $315 \mathrm{~cm}$ necrotische dunne darm na het openen van de breukzak

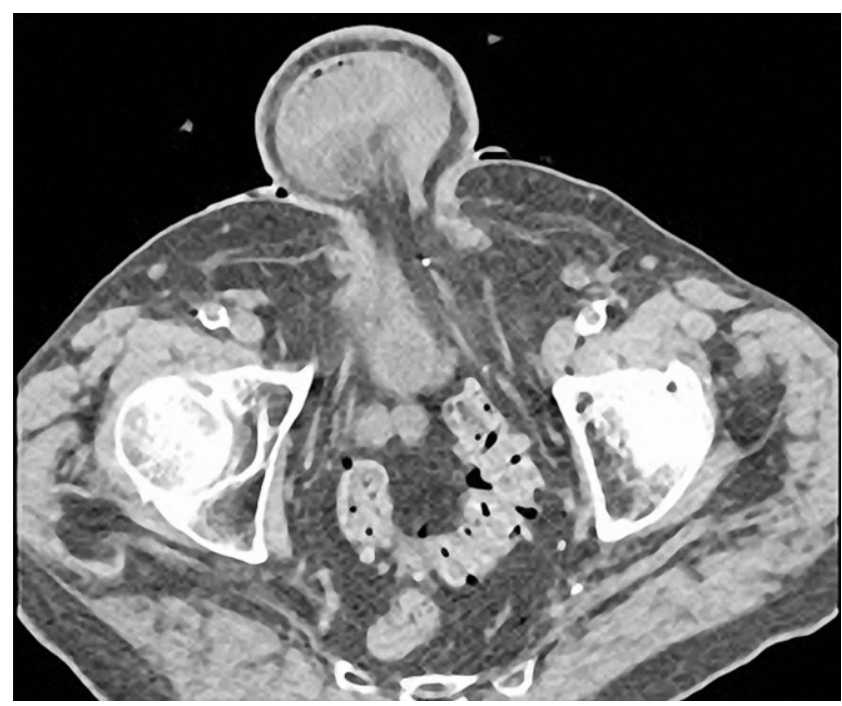

Figuur 2 Op de CT-scan is herniatie van dunne darm te zien

\section{Discussie}

SPC wordt vaak ingezet in de urologische praktijk en is niet zonder complicaties, zowel acuut als op langere termijn. De meest voorkomende acute complicaties zijn bloeding en darmperforatie [1, 2]. Andere kortetermijncomplicaties zijn infecties, blaasspasmen, obstructie of knikken van de katheter, luxatie en lekkage [3]. Langetermijncomplicaties zijn blaascarcinomen, blaasstenen en urethrale urinelekkage $[3,4]$. Twee studies beschrijven een 30dagenmortaliteit na plaatsing van $0,8-1,8 \%$ door darmperforaties $[1,2]$. De hernia die in deze casus wordt beschreven, is aanzienlijk zeldzamer.

Ons literatuuronderzoek laat zes casus zien met een littekenbreuk na SPC [5-9]. Vermeende risicofactoren die kunnen leiden tot een littekenbreuk zijn hardnekkige obstructie van de blaas, chronische obstipatie en chronische longziekten of hoesten, vanwege de hoge intra-abdominale druk [5]. Plaatsing van de SPC door een caudaal stuk van het peritoneum kan ervoor zorgen dat, na verwijdering van de SPC, door een verhoogde buikdruk een herniatie van het peritoneum en de buikinhoud kan plaatsvinden [7]. Het SPC-fisteltraject verloopt dan deels intraperitoneaal, en niet extraperitoneaal, zoals bij een normale positie van een SPC (fig. 4). In de door ons beschreven casus fungeerde het peritoneum als breukzak en was het fisteltraject waarschijnlijk wel extraperitoneaal gelegen. Een herniatie van de dunne darm door de breukpoort van de SPC, zoals in de hier opgevoerde casus, is nooit beschreven. Herniatie, strangulatie en dunnedarmobstructie die worden veroorzaakt door littekenbreuken van intraperitoneale poorten zijn wel gemeld na laparoscopie en peritoneale dialyse $[9,10]$. Een studie die werd uitgevoerd door de American Association of Gynaecologic Laparoscopists toonde een incidentie van 
Figuur 4 Plaatsing van een SPC door het peritoneum. Links: fisteltraject door het peritoneum. Rechts: breukpoort door het fisteltraject
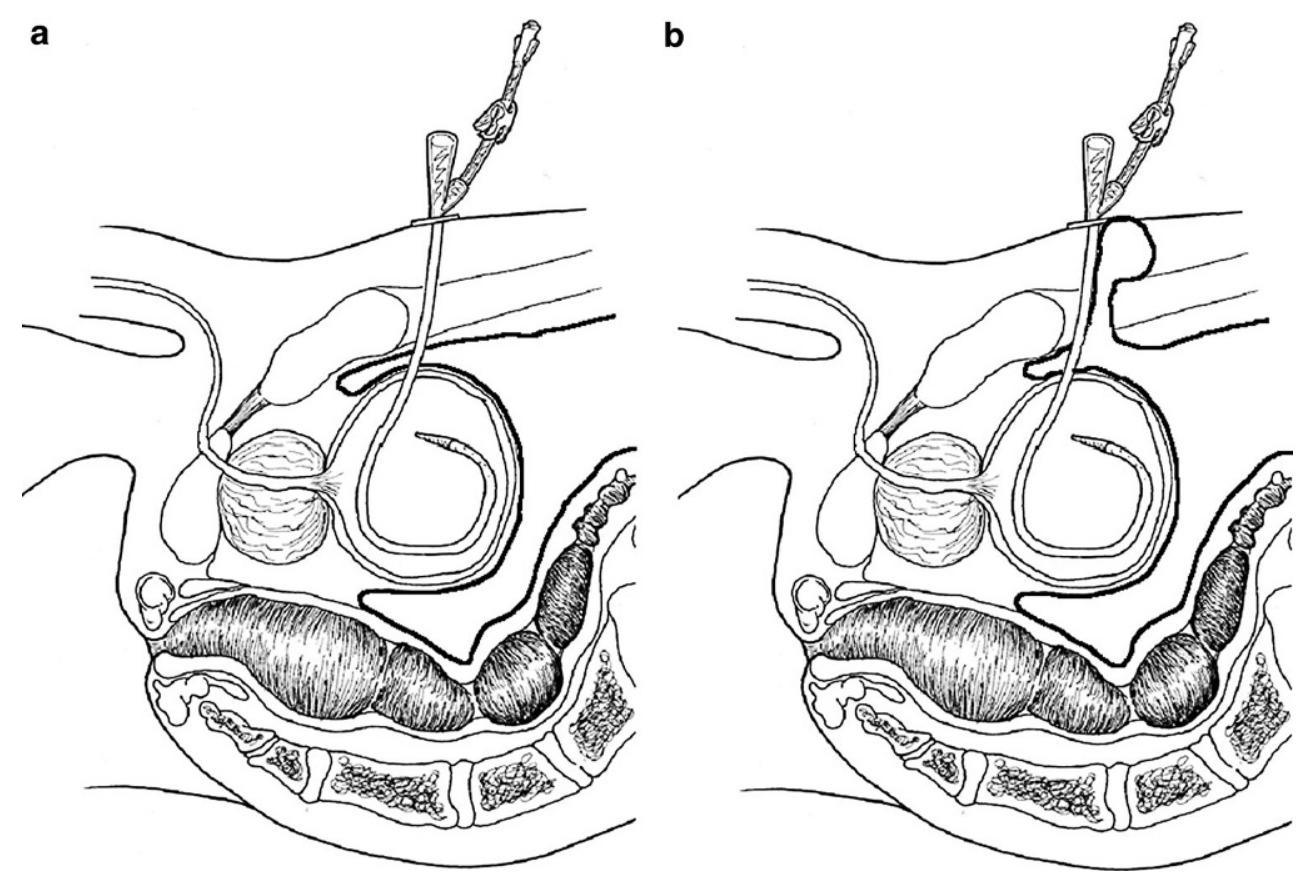

littekenbreuken na laparoscopie van $0,021 \%$. Een littekenbreuk kwam slechts in 2,7\% van de gevallen voor bij een trocarpoort kleiner dan $8 \mathrm{~mm}$, zoals het geval is bij een suprapubische katheter.

\section{Conclusie}

Een beklemde herniatie van dunne darm na suprapubische katheterisatie is een zeldzame, maar potentieel ernstige complicatie. Mogelijk kan tijdige chirurgische correctie verdere problemen, zoals in deze casus, voorkomen.

Open Access This article is distributed under the terms of the Creative Commons Attribution 4.0 International License (http:// creativecommons.org/licenses/by/4.0/), which permits unrestricted use, distribution, and reproduction in any medium, provided you give appropriate credit to the original author(s) and the source, provide a link to the Creative Commons license, and indicate if changes were made.

\section{Literatuur}

1. Sheriff MK, Foley S, McFarlane J, Nauth-Misir R, Craggs M, Shah PJ. Long-term suprapubic catheterisation: clinical outcome and satisfaction survey. Spinal Cord. 1998;36:171-6.
2. Ahluwalia RS, Johal N, Kouriefs C, Kooiman G, Montgomery BS, Plail RO. The surgical risk of suprapubic catheter insertion and long-term sequelae. Ann R Coll Surg Engl. 2006;88(2):210-3.

3. Hunter KF, Bharmal A, Moore KN. Long-term bladder drainage: suprapubic catheter versus other methods: a scoping review. Neurourol Urodyn. 2013;32:944-51.

4. Nomura S, Ishido T, Teranishi J, Makiyama K. Long-term analysis of suprapubic cystostomy drainage in patients with neurogenic bladder. Urol Int. 2000;65:185-9.

5. Mehta A, Makris A, Saad A, Callaghan PS. Incisional hernia after suprapubic catheter insertion. BJU Int. 1999;84:526-7.

6. Rao AR, Hanchanale VS, Sharma M, et al. Incisional hernia around the suprapubic catheter: an unusual complication. Hernia. 2007;11:61-2.

7. Nabi G, Aron M, Gupta NP. Incisional hernia after suprapubic trocar cystostomy. Urol Int. 2003;70:249-50.

8. Dowdall JF, Winter DC, Kirwan WO. Incisional hernia following supra-pubic catheterisation. Ir Med J. 2001;94:55.

9. Lobel RW, Sand PK. Incisional hernia after suprapubic catheterization. Obstet Gynecol. 1997;89:844-6.

10. Montz FJ, Holschneider CH, Munro MG. Incisional hernia following laparoscopy: a survey of the American association of gynecologic laparoscopists. Obstet Gynecol. 1994;84:881-4.

Robin Hoendervangers aios urologie

dr. Eric H.G.M. Oomens uroloog

dr. Joost A.P. Leijte uroloog

dr. Deric K.E. van der Schoot uroloog 